\title{
PENINJAUAN K3 DI PROYEK PEMBANGUNAN PERUMAHAN DIKOTA PALOPO
}

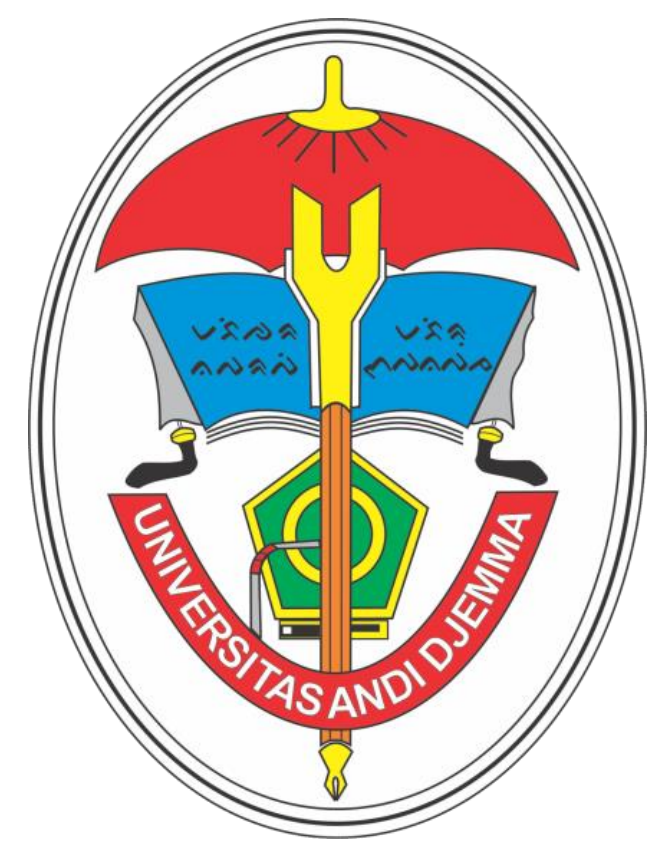

OLEH :

KELOMPOK I

ANALTA FATRAH HAKIM (20.023.22.201.160)

MUH. SIGIT SETIAWAN S. (20.023.22.201.146)

SULKIFLI (20.023.22.201.159)

YUYUN SADDENG (20.023.22.201.144)

FAKULTAS TEKNIK JURUSAN SIPIL UNIVERSITAS ANDI DJEMMA 


\section{KATA PENGANTAR}

Puji dan syukur kami panjatkan kehadirat Allah SWT, dimana yang sudah memberikan rahmat serta karunia-Nya kepada kami sehingga kami dapat berhasil menyelesaikan laporan ini tepat pada waktunya ini.

Dimana dalam laporan hasil peninjauan ini Kami menyadari jika laporan ini masih jauh dari kata sempurna. Oleh karenanya, kritik dan saran dari seluruh pihak yang bersifat membangun selalu kami harapkan demi kesempurnaan laporan ini.

Akhir kata, kami sampaikan terima kasih kepada seluruh pihak yang telah berperan dalam penyusunan laporan ini mulai dari awal sampai akhir. Semoga Allah SWT senantiasa meridhoi segala bentuk usaha kita. Amin

Palopo, Juli 2021

Penyusun 


\section{DAFTAR ISI}

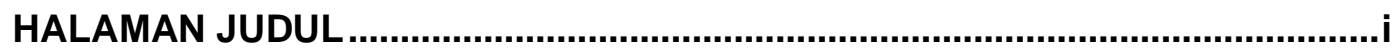

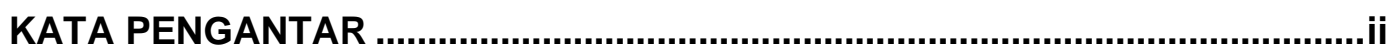

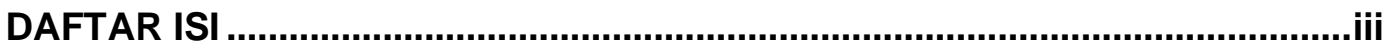

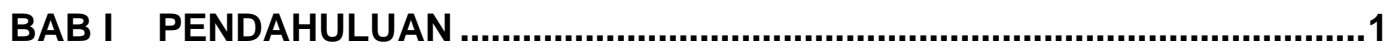

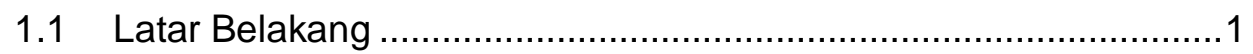

1.2 Maksud dan Tujuan .............................................................. 1

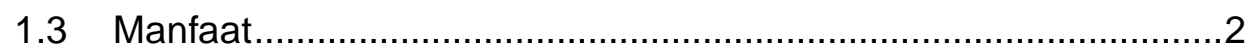

BAB II TINJAUAN TEORI DAN REGULASI ...................................................3

2.1 Tinjauan Umum ...................................................................

2.2 Ruang Lingkup K3 Proyek Konstruksi ......................................

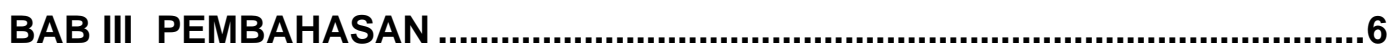

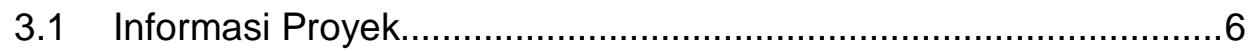

3.2 Item-item Pekerjaan Konstruksi Proyek...................................... 6

3.3 Hasil Observasi .........................................................................

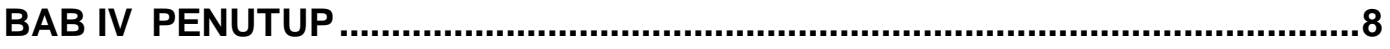

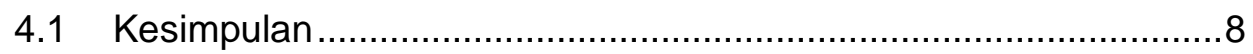

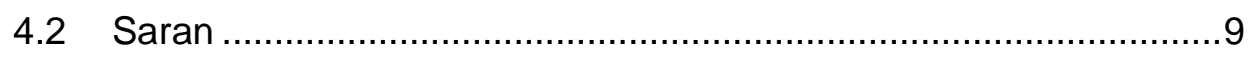

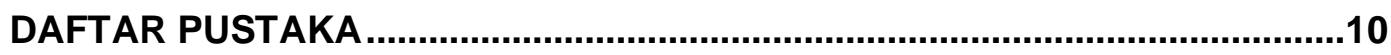




\section{BAB I \\ PENDAHULUAN}

\subsection{Latar Belakang}

Kesehatan dan Keselamatan Kerja (K3) adalah suatu pemikiran dan upaya untuk menjamin keutuhan dan kesempurnaan baik jasmani maupun rohaniah tenaga kerja pada khususnya, dan manusia pada umumnya, hasil karya dan budaya untuk menuju masyarakat adil dan makmur, serta menciptakan perlindungan dan keamanan dari resiko kecelakaan dan bahaya baik fisik, mental maupun emosional terhadap pekerja, perusahaan, masyarakat dan lingkungan.

Menerapkan program K3 dalam lingkungan kerja dengan tujuan agar setiap tenaga kerja berhak untuk mendapatkan jaminan keselamatan dan kesehatan kerja. Perlindungan tenaga kerja dari bahaya dan penyakit akibat kerja atau lingkungan kerja sangat dibutuhkan sehingga pekerja merasa aman dan nyaman dalam menyelesaikan pekerjaannya.

sehingga diharapkan dapat meningkatkan kepuasan kerja bagi pekerja, untuk dapat bekerja sebaik mungkin dan juga dapat mendukung keberhasilan serta target dalam pekerjaan dapat tercapai.

\subsection{Maksud dan Tujuan}

Kuliah Lapangan ini dilakukan untuk mengetahui apa saja proses atau masalah yang terjadi pada saat pembangunan perumahan subsidi yang ada diKota Palopo ini, sehingga dapat diketahui resiko apa saja yang terjadi pada saat pembangunan. Kemudian dapat ditentukan solusi yang tepat untuk mengatasi permasalahan yang ada.

1. Memperhatikan faktor-faktor risiko yang bisa terjadi dalam proses pelaksanaan pembangunan Perumahan subsidi yang ada diKota Palopo.

2. Mengetahui secara langsung metode Penerapan dalam Sistem Manajemen Keselamatan dan Kesehatan Kerja (SMK3) yang ada dilapangan kerja pembanguna perumahan.

3. Mengatahui resiko para pekerja dalam pembangunan perumahan.

\subsection{Manfaat}


Dengan adanya laporan kuliah lapangan ini, diharapkan dapat menambah wawasan para pembaca agar lebih memperhatikan keselamatan dan Kesehatan kerja dilapangan, serta bisa dapat bermanfaat untuk sesama dalam hal mengenai penerapan keselamatan dan kesehatan kerja (K3). Dalam melaksanakan penerapan K3 dengan penuh disiplin oleh para pekerja tentu dapat sangat bermanfaat untuk para pekerja itu sendiri sehingga tidak ada resiko atau hal yang tidak diinginkan terjadi dilapangan kerja. 


\section{BAB II \\ TINJAUAN TEORI DAN REGULASI}

\subsection{Tinjauan Umum}

K3 berperan untuk menjamin setiap tenaga kerja yang mendapat perlindungan dari kesehatan dan keselamatan selama bekerja, menjamin setiap sumber produksi yang layak dan aman digunakan sehingga mengurangi resiko kerugian yang di akibatkan oleh kecelakaan kerja.

Adanya kewajiban menyelenggarakan $\mathrm{K} 3$ di dalam proses pekerjaan dilapangan bertujuan untuk mencegah terjadinya kecelakaan dan penyakit akibat dari aktivitas di tempat kerja serta melindungi semua sumber produksi agar dapat digunakan secara efektif.

Pelaksanaan K3 juga memiliki beberapa tujuan khusus seperti poin-poin di bawah ini:

- Mencegah dan melindungi kecelakaan kerja.

- Mencegah timbulnya beragam penyakit akibat kerja, baik itu dalam bentuk fisik, psikis, infeksi, keracunan atau penularan.

- Meningkatkan kesejahteraan, kesehatan dan perlindungan terhadap para pekerja baik selama ataupun setelah masa kerja.

- Membuat para pekerja agar optimal dalam bekerja.

- Menciptakan sistem kerja yang aman.

- Memastikan bahwa kondisi alat kerja aman, nyaman dan layak untuk digunakan.

- Mencegah kerugian akibat terjadinya kecelakaan kerja.

- Melakukan pengendalian terhadap terhadap resiko-resiko yang ada di lingkungan kerja.

- Memelihara kebersihan, kesejahteraan dan ketertiban lingkungan kerja dan lingkungan sekitarnya.

\subsection{Ruang Lingkup K3 Proyek Konstruksi}

Keselamatan dan Kesehatan Kerja (K3) adalah semua kondisi dan faktor yang dapat berdampak pada keselamatan dan kesehatan kerja tenaga kerja maupun orang lain (kontraktor, pemasok, pengunjung dan tamu) tempat kerja. 
Penerapan prinsip K3 di proyek sangat perlu diperhatikan dalam pekerjaan konstruksi. Pelaksana konstruksi harus mengetahui dan menerapkan prinsipprinsip kerja sesuai ketentuan K3 di lingkungan proyek.

Adapun yang harus diketahui dalam Keselamatan dan kesehatan kerja konstruksi bangunan yaitu,

1. Karakteristik kegiatan proyek konstruksi bangunan

2. Jenis-jenis bahaya pada kegiatan konstruksi bangunan

3. Unsur-unsur terkait pada kegiatan konstruksi bangunan

4. Strategi penerapan K3 pada proyek konstruksi bangunan

5. Elemen program K3 proyek konstruksi bangunan

6. Pengawasan pelaksanaan K3 proyek kontruksi bangunan. 


\section{BAB III \\ PEMBAHASAN}

\subsection{Informasi Proyek}

Berikut uraian hasil monitoring dan evaluasi pelaksanaan K3 dalam proses Pembangunan perumahan diKota Palopo tanggal 15 - 26 Juli 2021, yaitu : Nama Proyek: Pembangunan Perumahan Subsidi.

Deskripsi Proyek: Perumahan Tempat Tinggal.

Nilai Proyek: Tergantung harga jual rumah, harga standar kisaran Rp.156.000.000 per unit, sudah termasuk IMB.

Jumlah Pekerja: kurang lebih 13 sampai 17 Orang.

Sumber dan tahun Anggaran: Dari Perseruan Terbatas (PT) dan Proyek ini dimulai tahun 2019 sampai sekarang.

Untuk saat ini jumlah rumah yang sementara dibangun sebanyak 44 unit.

\subsection{Item-item Pekerjaan Konstruksi Proyek}

Secara garis besar konstruksi yang digunakan dalam pembangunan perumahan subsidi diKota Palopo antara lain:

- Excavator.

- Baja ringan.

- Baja tulangan.

- Molen cor.

- Dan konstruksi lain yang tidak disebutkan satu persatu.

\subsection{Hasil Observasi}

Hasil Observasi pada tinjauan pembangunan Perumahan Subsidi diKota Palopo. Keselamatan kerja pada pembangunan perumahan ini tidak dilakukan dengan baik secara K3. Karena para pekerja sebagian besar tidak memakai Alat Pelindung Diri (APD), dan hanya ada sebagian yang memakai sepatu dan kos tangan yang standar keselamatannya kurang.

Dalam hal ini para pekerja seharusnya memakai atribut pelindung K3 agar menghindari suatu resiko yang tidak diinginkan bersama. Adapun para pekerja kedepannya harus itu lebih memikirkan keselatan dalam pekerjaan yang 
mempunyai resiko yang tak terduga, sehingga dengan memakainya alat pelindung diri (APD) dapat lebih sefety dan mengurangi resiko yang tidak diinginkan pada saat bekerja dilapangan.

Adapun Dokumentasi pembangunan perumahan ini:
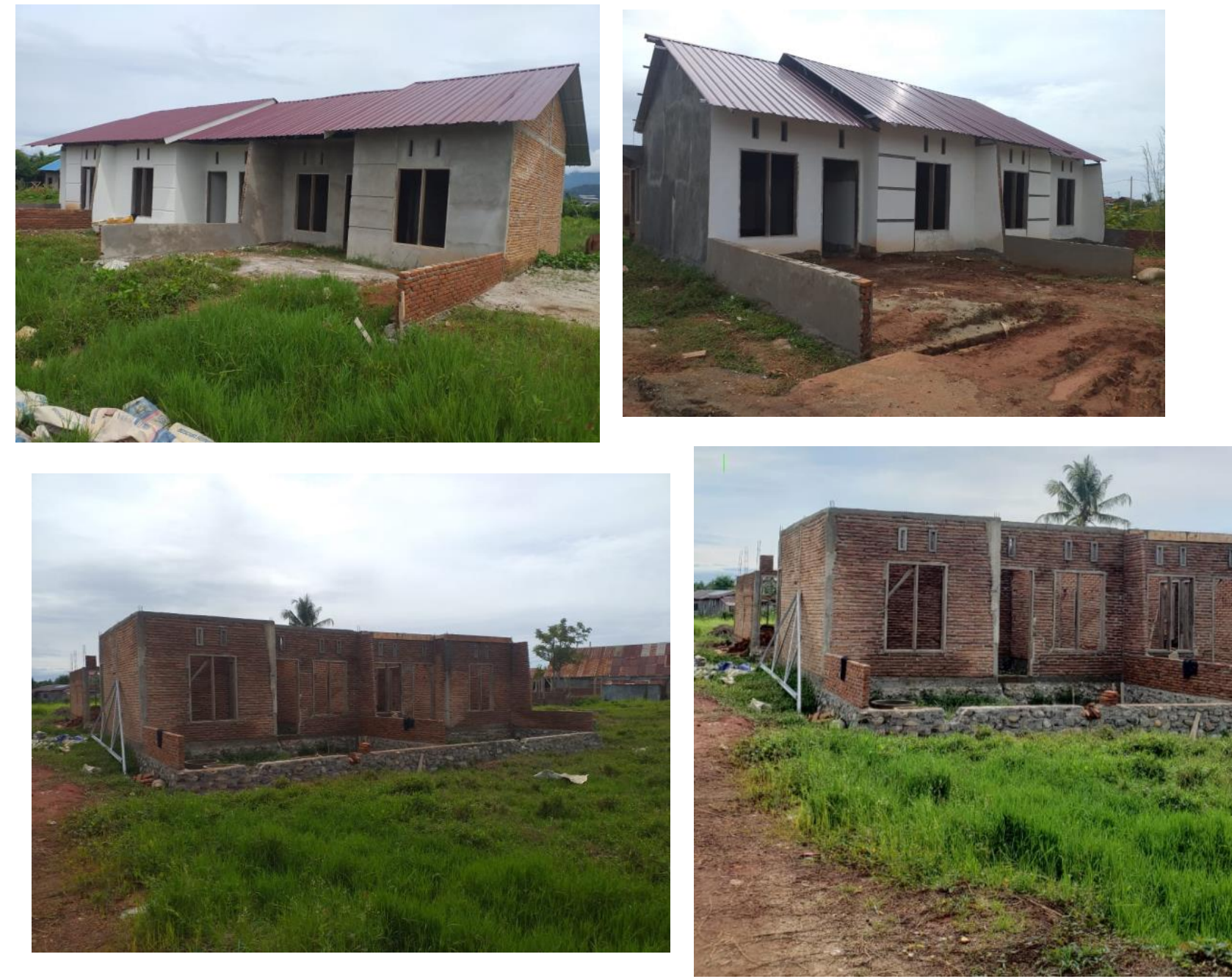


\section{BAB IV \\ PENUTUP}

\subsection{Kesimpulan}

Setiap Tenaga Kerja berhak mendapat perlindungan atas keselamatannya dalam melakukan pekerjaan untuk kesejahteraan hidup dan meningkatkan produksi serta produktifitas nasional.

Pelaksanaan Kesehatan dan Keselamatan Kerja (K3) adalah salah satu bentuk upaya untuk menciptakan tempat kerja yang aman, sehat, bebas dari pencemaran lingkungan, sehingga dapat mengurangi dan atau bebas dari kecelakaan kerja dan penyakit akibat kerja yang pada akhimya dapat meningkatkan efisiensi dan produktivitas kerja.

1. Keselamatan dan kesehatan kerja (K3) merupakan ilmu pengetahuan dalam upaya untuk menciptakan suasana bekerja yang aman, nyaman, dan tujuan akhirnya yaitu mencapai produktivitas setinggi-tingginya.

2. Perlengkapan alat pelindung diri dalam melakukan pekerjaan seperti :

- Pakaian kerja.

- Sepatu kerja.

- Kacamata kerja.

- Sarung tangan.

- Helm pelindung kepala.

- Penutup telinga.

- Masker

\subsection{Saran}

Kesuksesan penerapan K3 pada konstruksi pembangunan tidak lepas dari peran berbagai pihak yang saling terlibat, berinteraksi dan bekerja sama. Masing masing pihak mempunyai tanggung jawab bersama yang saling mendukung untuk keberhasilan pelaksanaan proyek konstruksi jalan raya yang ditandai dengan evaluasi positif dari pelaksanaan program K3. Saran yang hendak diperhatikan adalah : 
1. Perilaku K3 perlu ditingkatkan lagi dengan berbagai jenis promosi dan training- training pelatihan $\mathrm{K} 3$ secara rutin.

2. Adanya poster atau slogan $\mathrm{K} 3$, serta tanda - tanda peringatan bahaya ditempat kerja terutama yang berpotensi menjadi penyebab kecelakaan kerja.

3. Para kontraktor hendaknya melaksanakan sistem K3 walaupun dalam tingkat yang paling sederhana untuk menghindari terjadinya kecelakaan kerja. 


\section{DAFTAR PUSTAKA}

[1] http://jurnal-k3lh.web.id/2014/12/26/pengawasan-k3-konstruksi

[2] https://upp.ac.id/blog/tujuan-k3-keselamatan-dan-kesehatan

[3] System Maintenance by : Diskominfo Banda Aceh

[4] Anonim.2008.ManajemenRisikokesehatandankeselamatankerja./200 8/01/manajemen-risiko-untuk-k3.

[5] Anonim.2009.DefinisidanManfaatPenerapanManajemenRisikojurnals dm.blogspot.com/2009/09.

[6] Ariagusti.2011.ManajemenRisikoDalamKeselamatan\&KesehatanKerj a.ariagusti.w ordpress.com/2011/01/07/.

[7] Ariagusti.2011.ManajemenRisikoK3diPerusahaan.BlogDosenKesehat anMasyaraka t.html.

[8] Ishak,Aulia.2004.ManajemenK3DalamUpayaMeningkatkanProduktivit asKerja.repository.usu.ac.id/bitstream/123456789/1458/1/industriulia 3.

[9] Mansyur,Muchtaruddin.2007.ManajemenRisikoKesehatanDiTempatK erja.docs.goo gle.com/viewer?a=v\&q=cache:InJ_9_qznQIJ:indonesia.

[10] Mulyadi,HendraDicky.2011.ManajemenRisiko.dickyhendramulyadi@y ahoo.com

[11] Rachmadi.2011.ManajemenResiko(JanganTakutDenganResiko).sho wthread.php?ti $d=16221$.

[12] Marzaman, L. U., Hafid, Z., Fisu, A. A., \& Nurhijrah, N. (2021). Planning Concept of Lalebbata: Combining Heritage, Policy and Participation. PENA TEKNIK: Jurnal IImiah IImu-IImu Teknik, 6(1), 3947.

[13] Fisu, A. A. (2016). Potensi Demand Terhadap pengembangan Kanal Jongaya \& Panampu Sebagai Moda Transportasi (Waterway) di Kota Makassar. Jurnal Manajemen Transportasi \& Logistik, 3(3), 285-298.

[14] Tresidder, J. O., POWELL, T., MEYERS, D., \& BURRELL, J. (1968). THE LONDON TRANSPORTATION STUDY: METHODS AND TECHNIQUES. Proceedings of the Institution of Civil Engineers, 39(3), 433-464. 
[15] Ridley, T. M., \& Tresidder, J. O. (1970). The London transportation study and beyond. Regional Studies, 4(1), 63-71.

[16] Fisu, A. A. (2018). Analisis Kebutuhan Fasilitas Sisi Laut Pelabuhan terminal Khusus PLTGU Lombok. PENA TEKNIK: Jurnal IImiah IImuilmu Teknik, 3(2), 197-206.

[17] Humang, W. P., \& Amrin, A. (2018). PENINGKATAN AKSES JALAN UNTUK MENUNJANG DISTRIBUSI HASIL PRODUKSI KOTA TERPADU MANDIRI (KTM) AIR TERANG KABUPATEN BUOL. PENA TEKNIK: Jurnal IImiah IImu-IImu Teknik, 1(2), 111-124.

[18] Humang, W. P., \& Zulfadly, A. Z. A. (2016). Analisis Keterpaduan Moda Transportasi Angkutan Penyeberangan Dengan Jalan Raya di Pelabuhan Bajoe Kab. Bone. PENA TEKNIK: Jurnal IImiah IImu-IImu Teknik, 1(1), 27-38.

[19] Fisu, A. A. (2016). Analisis dan Konsep Perencanaan Kawasan Pelabuhan Kota Penajam Sebagai Pintu Gerbang Kab. Penajam Paser Utara kalimantan Timur. PENA TEKNIK: Jurnal IImiah IImuIImu Teknik, 1(2), 125-136.

[20] Fuller, D., Sahlqvist, S., Cummins, S., \& Ogilvie, D. (2012). The impact of public transportation strikes on use of a bicycle share program in London: Interrupted time series design. Preventive medicine, 54(1), 74-76.

[21] Marzaman, L. U., Hafid, Z. A., Fisu, A. A., \& Nurhijrah, N. (2019). PLACE MAKING WORKSHOP BATUPASI SUB DISTRICT PALOPO CITY. To Maega: Jurnal Pengabdian Masyarakat, 2(1), 1-8.

[22] Hidayat, A., \& Fisu, A. A. (2020). Konsep Arsitektur Panti Rehabilitasi Ketergantungan Narkotika \& Psikotropika Di Makassar, Pendekatan Arsitektur Postmodern Historiscm. PENA TEKNIK: Jurnal IImiah IImuIImu Teknik, 5(1), 31-43.

[23] Sulaiman, L., \& Fisu, A. A. (2020). Pengaruh Campuran Terhadap Kuat Tekan Beton Agregat Recycle. Rekayasa Sipil, 14(1), 35-42.

[24] HARYONO, H. (2015). COMPARATIVE ANALYSIS OF TRANSPORTATION SYSTEM IN AMERICA, ENGLAND, AND INDONESIA. Jurnal Manajemen Bisnis Transportasi dan Logistik, 1(3), 492-509.

[25] Rowangould, D., Karner, A., \& London, J. (2016). Identifying environmental justice communities for transportation analysis. Transportation Research Part A: Policy and Practice, 88, 151-162.

[26] Fisu, A. A. (2019). Merawat Nilai Membangun Kota.

[27] Marzaman, L. U., \& Fisu, A. A. (2020). Hunian Vertikal Kontainer Buruh Pt Kima Dengan Konsep Arsitektur Humanis. PENA TEKNIK: Jurnal IImiah IImu-IImu Teknik, 5(2), 91-103.

[28] Marzaman, L. U., Hafid, Z., \& FISU, A. A. MERAJUT CERITA DI KOTA TUA (REVITALISASI KAWASAN EX PASAR LAMA PALOPO).

[29] Fisu, A. A., \& Didiharyono, D. (2020, April). Economic \& Financial Feasibility Analysis of Tarakan Fishery Industrial Estate Masterplan. 
In IOP Conference Series: Earth and Environmental Science (Vol. 469, No. 1, p. 012002). IOP Publishing.

[30] Natsir, R. (2018). EVALUASI KINERJA SIMPANG BERSINYAL DI KOTA PALOPO. PENA TEKNIK: Jurnal IImiah IImu-IImu Teknik, 1(1), 95-100.

[31] Fisu, A. A. (2020). Analisis Perencanaan Pengembangan Fasilitas Terminal Khusus PLTU Nagan Raya Aceh.

[32] Marsus, B., Indriani, N. K., Darmawan, V., \& Fisu, A. A. (2020). PENGARUH PANJANG INFRASTRUKTUR JALAN TERHADAP PDRB DAN PERTUMBUHAN EKONOMI KOTA PALOPO.

[33] Fisu, A. A. (2019). 17 Tahun Kota Palopo: Kota, Manusia dan Para Penggerak.

[34] Nurhijrah, N., Fisu, A. A., Marzaman, L. U., \& Hafid, Z. KONSEP PENATAAN KAWASAN LALEBBATA SEBAGAI KAWASAN HERITAGE DI KOTA PALOPO. Jurnal Arsitektur ZONASI, 4(1).

[35] Fisu, A. A., \& Syabri, I. (2020). Demand Potential On Canal Utilization As Alternative Urban Transportation Medium In Makassar City.

[36] Marzaman, L. U., Hafid, Z., Fisu, A. A., \& Nurhijrah, N. (2021). Planning Concept of Lalebbata: Combining Heritage, Policy and Participation. PENA TEKNIK: Jurnal IImiah IImu-IImu Teknik, 6(1), 3947.

[37] Fisu, A. A. (2018). ANALISIS LOKASI PADA PERENCANAAN TERMINAL TOPOYO MAMUJU TENGAH. PENA TEKNIK: Jurnal IImiah IImu-IImu Teknik, 3(1), 1-12.

[38] FISU, A. A. STUDI AWAL LOKASI RENCANA PELABUHAN DI TELUK PRIGI KABUPATEN TRENGGALEK.

[39] Arrang, A. T. (2016). TINJAUAN KESELAMATAN LALU LINTAS TERHADAP GEOMETRIK JALAN RUAS TORAJA-PALOPO (STUDI KASUS STA. 379+ 170-STA. 383+ 300). PENA TEKNIK: Jurnal IImiah IImu-IImu Teknik, 1(2), 149-154.

[40] Fisu, A. A., Tufail, D. N., Procyoniana, S. B., \& Nugraha, R. M. (2019). TINJAUAN TRANSPORTASI PADA KAWASAN KOMERSIL (STUDI KASUS JALAN CIHAMPELAS KOTA BANDUNG). 